America for the Referee Board of the Council of Pharmacy and Chemistry of the American Medical Association. They found that large doses $(0.75$ to $1.5 \mathrm{~g}$., or 12 to $20 \mathrm{gr}$., daily) occasionally produced hyperacidity and increased intestinal putrefaction. There were no such effects with small doses. It can, therefore, be safely used in ordinary amounts by patients with peptic ulcer. An antipyretic action is not described, but in large dose-e.g., $10 \mathrm{gr}$. (20 tablets) - it might well have one, judging by its composition.

\section{Hepatic Cirrhosis}

Q.-Is there any treatment available along new lines for hepatic cirrhosis, such as are envisaged in your annotation of Sept. 9 (p. 346)? Dietary considerations in this case can, I believe, be solved in accordance with that annotation, but tell me which preparation " containing all the members of the vitamin B complex carefully balanced" is recommended? Is methionine available for clinical use?

A.- The analogy between cirrhosis of the liver in man and hepatic injury from dietary deficiències in animals can be overstrained, and there is little evidence that cirrhosis in man is specifically improved by vitamins or food principles. The improvement is not greater than might be expected from good nutrition in any chronic disease. Yeast is probably the best-balanced source of the vitamin B complex, and it is possible to give as much as $3 \mathrm{oz}$. a day in the form of bakers yeast, dried yeast, or food yeast. Unfortunately the total vitamin content is not very high. In any event no convincing results have been seen in a controlled therapeutic trial of yeast in hepatic cirrhosis (unpublished observations). More concentrated proprietary preparations of the $\mathrm{B}$ complex are available in the form of wheat germ, autolysed yeast, or extracts of rice polishings. Liver extract is also a very good source. Alternatively, the separate elements in the complex-aneurin, riboflavin, and nicotinic acid-may be given simultaneously in high dosage, but this means omitting elements of the B complex such as folic acid, and is likely to be extraordinarily costly. No report of any controlled trial of methionine in cirrhosis is available, but it is known that it has not had any noteworthy success in large-scale trials in infective hepatitis. A recent fin chemical manufacturer's catalogue quoted methionine at $7 \mathrm{~s}$. gramme. The therapeutic dose is of the order of $5 \mathrm{~g}$., or $35 \mathrm{~s}$ a day. There is reason to believe that stocks are not sufficient for clinical trial apart from officially sponsored research, nor are they likely to become available during the -war in view of the high cost of production of methionine and the scant evidence of therapeutic effects in man.

\section{Nephrotic Syndrome in Childhood}

Q.-Has the work of Farr et al. in America on casein hydrolysate in the treatment of the nephrotic syndrome in children proved of any use in nephrotic crises, and if so, where could I get a suitable preparation?

A.-Farr believed that injections of casein hydrolysate were of special value in the treatment of infectious episodes in the nephrotic syndrome in childhood, but no confirmation of his work has been published. A theoretical disadvantage of protein hydrolysates in the treatment of hypoproteinaemia of renal origin is the fact that, if the material is given parenterally, large quantities of water and mineral salts are given at the same time. The final concentration of hydrolysate administered is usually $5 \%$ or less, so that $1,000 \mathrm{c.cm}$. of fluid must be given to inject $50 \mathrm{~g}$. of protein. Amounts of this order would need to be given for many days, and in practice this difficulty seems greatly to have limited the application of parenteral treatment to children with oedema. Oral therapy is often difficult owing to loss of appetite or nausea. More hope is therefore being placed in the possibility of using purified serum albumin for injection in these cases, but this is still a project for the future. Severa research groups are at present co-operating with British manufacturers on the preparation and use of protein hydrolysates, but the technique is still in the experimental stage, and there are apparently no preparations on the open market in this country.

\section{Oxalated Blood for Cell Counts}

Q.-Is the practice of sending blood (oxalated) by post for estimation of $\mathrm{Hb}$, cell count, etc., likely to give true results? It is presumed that the sample reaches the laboratory within about 15 hours after withdrawal from a vein.

A.-While oxalated blood is adequate for rough haemoglobin estimations and red cell counts, an accurate complete blood count cannot be carried out by this method, and it should be discouraged.

\section{B.M.R. Estimations and Thiouraci}

Q.-Are B.M.R. estimations essential in treating a patient with thiouracil provided a watch is kept on the white cell count?

A.-No. B.M.R. estimations are certainly useful, but in experienced hands they are not necessary. The general condition of the patient, his nervous state and autonomic function, his pulse rate, temperature chart, and skin temperature, are all important indications of progress. Probably the most important sign is his weight. It has been reported that the blood cholesterol (the absolute value of which is too variable to be useful) is valuable in a relative way, and that in any individual patient changes in blood cholesterol run parallel to changes in B.M.R. This statement has not been fully corroborated, but appears often to be true.

Treatment of Rodent Ulcer

Q. -What is the best line of treatment for a somewhat doubtful rodent ulcer, apart from excision?

A.--Provided that there are reasonable grounds for the diagnosis of rodent ulcer and that the situation is appropriate, intensive radiotherapy is called for, which can be carried out only by an expert. It is often desirable to remove a small portion for microscopical examination before the treatment is carried out.

\section{Disturbed Sleep in a Child}

Q.-Could you advise me on the treatment or causation of disturbed sleep in a boy of 3? After three to four hours' sleep the child begins rocking in the "knee-elbow" position, eventually waking up after the bedclothes have been thrown off. If laid on his side he quietens for a quarter to half an hour, and then begins again. So far no treatment has been of any avail.

A.- Should there be any doubt of the child's intelligence not being normal, mental testing even at this age can be done by an educational psychologist at a child guidance clinic. In children of normal intellect in the first three years rhythmic movements in the state between sleep and wakefulness are common. The first essential is to reassure the parents that such movements, though annoying, are of no importance and will disappear. To hasten their departure and help to break the habit, a sedative for two or three weeks to provide deeper sleep is the only form of treatment necessary. For a child of 3 years luminal gr, $1 / 4$, or, if well tolerated, even gr. $1 / 2$, at bedtime is usually effective.

\section{LETTERS, NOTES, ETC.}

\section{Mental Hospitals}

Dr. Otho FitzGerald (Shenley Hospital, Herts) writes: It surprised me when reading the Journal of Oct. 28 to note the title or reference of "Asylum Doctors' Pay " applied to the letter which was signed "A.M.O." Apparently your attention has not been drawn to Section 20 of the 1930 Mental Treatment Act, which rules that the term "asylum" should be replaced by the term "mental hospital." I am sure you will admit the wisdom of that ruling, since institutions catering for the mentally disordered are no longer merely places of rest and detention but provide active and specific forms of treatment. "A.M.O." pleads that " niggardly remuneration is not likely to increase the repute of a branch of medicine which in the past has not enjoyed the prestige it deserves." It is surely very unkind of you, Sir, further to lash poor "A.M.O.'s" injured sense of prestige by insinuating that he is employed in institutions which are worthy only to be designated " asylums."

\section{Flea Bites}

Dr. Thomas Fentem (Bushey, Herts) writes: I have read the note under the above heading (Oct. 14, p. 520). Unfortunately I am one $N$ of those who appear to attract fleas, and it may be of some comfort to others similarly attractive to think that may be one reason why others are immune. However, I found years ago that if I took a 5 -grain tablet of sulphur, at first daily and then at longer intervals, $\overrightarrow{\mathrm{N}}$ the flea, though he might irritate by running about, would not bite. A few drops of chloroform, a sort of depth charge, in the neigh- $\omega$ bourhood of his walk but on the outside of the clothes, sufficed to put him out.

Arsenic in Malaria : Correction

Prof. D. B. BLACKLOCK writes: By an oversight on my part a $\mathscr{乛}$ phrase of some importance was omitted from the typescript of my : letter published in your issue of Nov. 18. The fourth paragraph should read: "This evidence, so far as it goes, is against the probability of organic arsenic alone, in the form of neokharsivan $\mathbb{\mathbb { D }}$ and in the dosage suggested, proving curative. . ." The phrase which was omitted is in italics.

\section{Pure-tone Audiometer: Correction}

Dr. Mary D. SheriDan writes: May I correct an inaccuracy in my article of Aug. 26, to which my attentoin has recently been drawn? The first pure-tone audiometer in this country was used by Dr. A. W. G. Ewing at Manchester University in 1927. Dr. Ewing's original paper on "High-frequency Deafness" was read before the Physical Society in London in 1930. His book Aphasia in Children, describing still earlier researches in this subject, was also published in 1930. 